\title{
Hokkien Chinese Borrowings on Cookery in Tagalog
}

\author{
Xuebo Cui \\ English Department, Yanbian University, Yanji, China \\ Email: xuebocui@yahoo.com
}

\begin{abstract}
This paper attempts to examine the Tagalog loanwords of Hokkien origin in the domain of cookery through the semantic analyses. Taxonomic analysis to the Hokkien loanwords on cookery provided superordinate and subordinate levels which showed the hierarchical relationships of the lowest-level categories to the highest-level ones. Percentages of loanwords under each category on three different levels were taken into consideration. Based on the analysis, generalization on the nature of loanwords in the domains was made. The findings reveal the fact that these terms of food and ways of cooking which were commonly identified with the Hokkien Chinese were readily accepted by the Tagalog speakers.
\end{abstract}

Index Terms - Min Nan Chinese, Hokkien, tagalog, loanwords, cookery, taxonomic analysis

\section{INTRODUCTION}

The practice of taking a word from a foreign language and introducing it into another is called 'borrowing' and the words thus 'borrowed' are known as loan words. It is worth mentioning from the outset that, as Crystal (1997, p.332) observed, since no language ever took a word from another language with the intention of one day returning it, and since such words are never returned, even once they have outstayed their welcome in the borrowing language, both of these terms are misnomers. It is more accurate to speak of one language copying words from another language (Crowley, 1997, p.155). It is also important to understand that this is not a modern phenomenon brought about by globalization but has always taken place whenever different language communities come into contact with each other.

The Tagalog language is an Austronesian language spoken as a first language by a third of the population of the Philippines and as a second language by most of the rest (Philippine Census, 2000). It is the first language of the Philippine region IV (CALABARZON and MIMAROPA) and of Metro Manila. Its standardized form, commonly called Filipino, is the national language and one of two official languages of the Philippines. It is related to - though not readily intelligible with —other Austronesian languages such as Malay, Javanese, and Hawaiian.

Tagalog, due to its history of connections with the rest of Asia, and the influence of European colonization, has developed a unique vocabulary since its inception from its Austronesian roots. Tagalog vocabulary is composed mostly of words of Austronesian origin with borrowings from Spanish, Hokkien Chinese, English, Malay, Sanskrit, Arabic, Tamil, Persian, Kapampangan, languages spoken on Luzon, and others, especially other Austronesian languages. Thorp (1972) reveals that fourty-two percent of Tagalog lexical entries are of foreign origin and the remaining fifty-eight percent are Tagalog in origin. Among the fourty-two percent of foreign words, thirty-three percent are Spanish words, three percent are Min Nan Chinese (Hokkien), and four percent are Malay. The rest two percent are English, Sanskrit and Arabic origin.

Hokkien is a group of mutually intelligible Min Nan Chinese dialects spoken by many overseas Chinese throughout Southeast Asia. It is originated from the same dialect in southern Fujian and is mutually intelligible with the Hokkien in Taiwan. It is closely related to Teochew, though mutual comprehension is difficult, and somewhat more distantly related to Hainanese. The Amoy and Taiwanese prestige dialect are considered standards (Kane, 2006).

Beyer (1948) states the possibility of a racial link between the people of the Philippines and the ancestors of the Chinese by tracing the major migratory waves that occurred in the Philippines back to the Chinese mainland and Indo-China. The first wave of immigrants which came about 3000 B.C. or 5000 to 6000 years ago introduced a much advanced culture and craftsmanship. The second wave came during 1500 B.C., which brought practiced extensive dry agriculture and cultivated upland rice, taro, yams and other food crops. The third wave which took place between 800 and 500 B.C. was ascribed the construction of the rice terraces (Beyer, 1947, as cited in Yap, 1974, p.2). The latter wave of immigrants from mainland China which came at about 300 to 500 A.D. brought the Jar-Burial culture. The use of jars for burying the bones of ancestors was particularly identified with migrations from the province of Fukien. It is believed that the waves of migrations constitute the beginning of relationships between the ancestors of the Filipinos and of the Chinese which were mainly commercial. Heavy trading between the Chinese and the Filipino trader continued until the arrival of the Spaniards in 1521.

It is apparent that the single largest group of Chinese which has trade relations with Filipinos came from the province of Fukien. As a result, many Chinese loanwords, especially Hokkien were gained, some examples are as in Table 1. 
TABLE 1:

LIST OF TAGALOG LOANWORDS FROM HOKKIEN

\begin{tabular}{|c|c|c|}
\hline Tagalog & Hokkien & Meaning \\
\hline apo & a-kong & grandchild/ren in Tagalog; Grandfather in Kokkien \\
\hline ate & a-chí & eldest sister \\
\hline bakya & $\mathrm{ba} \square \mathrm{k}-\mathrm{kia} \square \mathrm{h}$ & wooden sandals \\
\hline batchoy & bah-chúi & pork in soup \\
\hline bihon & bí-hún & rice vermicelli \\
\hline bitsin & bī-cheng & monosodium glutamate \\
\hline daw & tao & He said/she said/they said/it was said/reportedly/supposedly \\
\hline ditse & dì-chí & second eldest sister \\
\hline hikaw & hì-kau & earrings \\
\hline jusi & hù-si & cloth made from pineapple fibers \\
\hline ingkong & a-kong & grandfather \\
\hline kuya & keh-ya & eldest brother \\
\hline lumpia & jūn-piá & spring rolls \\
\hline mami & bah-mī & meat and noodles in soup \\
\hline pancit & piān-ê-si $\square \mathrm{t}$ & noodles with sauce \\
\hline petsay & pe $\square$ h-chhài & Chinese cabbage \\
\hline pesa & $\mathrm{sa} \square \mathrm{h}$ & plain boiled \\
\hline santse & san-chí & third eldest sister \\
\hline siyansi & chian-sî & spoon-like kitchen turner/spatula \\
\hline siyopaw/siopao & sio-pau & dough ball filled with pork/beef/carabao meat \\
\hline sotanghon & so-tang-hun & cellophane noodles \\
\hline tikoy & tih-ke & Chinese New Year's cake \\
\hline tokwa & tāu-koa & soybean curd \\
\hline totso & tāu-iû-chhò $\square$-hî & sauteed fish \\
\hline toyo & tāu-iû & soy sauce \\
\hline tausi & tāu-si & fermented black beans \\
\hline
\end{tabular}

The present paper studies the Tagalog loanwords of Hokkien origin, especially those in the domains of cookery. Specifically, the study will concentrate on the semantic analysis of the Tagalog loanwords of Hokkien origin on cookery. The number of loanwords in the domain of cookery is rather large, and is the most homogeneous of the loanwords (Yap, 1974, p8). The study is important because of its relevance to Philippine culture and national development. In addition, the long influence of Chinese on Philippine life and culture can be revealed.

\section{SEMANTIC ANALYSIS OF HOKKIEN LOANDS ON COOKERY}

Preliminary research investigates that there are one hundred sixty three Hokkien Chinese loanwords in present Tagalog (Yap, 1974, p. v). There is considerable number of loanwords in the domain of cookery in Tagalog which includes items whose origins are unquestionably Hokkien.

Yap (1974) applied a kind of semantic analysis - a taxonomic analysis to analyze the Tagalog loanwords of Hokkien origin on cookery.

Taxonomic analysis is commonly used in zoology and botany for the classification of flora and fauna. It classifies sets of contrasting categories hierarchically into successive levels or taxa, with the categories at any one level being included in a category at the next higher level (Frake, 1946, p. 196). More than two lower levels or taxa can belong to the next highest level or taxon (Bendix, 1966, p. 5). Taxonomies are said to be bi-dimensional: a horizontal one of discrimination and a vertical one of generalization.

Yap reveals that a great number of the Hokkien Loanwords on cookery is concentrated on raw, although the loanwords under the category of cooked constitute also a high percentage; the category instruments has the smallest number of loanwords. On a lower level of taxonomic analysis, the following categories have a higher ranking than others: meat, vegetables and soy bean products, indicating that the Tagalog borrowed heavily in these areas. The category boiled and steamed ranked highest under the level manner of cooking. These finding confirms the general impression that such manner of cooking is very common among the Hokkien people.

\section{A. Taxonomy of Hokkien Loanwords on Cookery}

Table 2 shows the taxonomic structure of the Hokkien loanwords on cookery. It contains three superordinate categories, and nineteen subordinate categories which are presented in a manner that can best capture the structural relationship that exits between them. 
TABLE 2:

TAXONOMY OF TAGALOG COOKERY TERMS OF HOKKIEN ORIGIN (YAP, 1974, P.144)

\begin{tabular}{|c|c|c|c|c|}
\hline \multirow[t]{18}{*}{ Food } & \multirow[t]{8}{*}{ Raw } & \multirow[t]{4}{*}{ Meat } & Pork cuts & tito \\
\hline & & & Beef cuts & goto \\
\hline & & & Fish \& seafood & tuwabak \\
\hline & & & Fowls & ulikba \\
\hline & & Vegetable & \multicolumn{2}{|l|}{ petsay } \\
\hline & & Soybean prod. & \multicolumn{2}{|l|}{ tokuwa } \\
\hline & & Rice prod. & \multicolumn{2}{|l|}{ bihon } \\
\hline & & Flour prod. & \multicolumn{2}{|l|}{ misuwa } \\
\hline & \multirow[t]{10}{*}{ Cooked } & Food preparation & \multicolumn{2}{|l|}{ toyo } \\
\hline & & \multirow[t]{5}{*}{ Type of food } & Meat & goto \\
\hline & & & Vegetable & petsay \\
\hline & & & Soy bean prod. & taho \\
\hline & & & Rice prod. & bihon \\
\hline & & & Flour prod. & miswa \\
\hline & & \multirow[t]{4}{*}{ Manner of cooking } & Fried & ukoy \\
\hline & & & Boiled steamed & siyopaw \\
\hline & & & Stewed & humba \\
\hline & & & Soupy & mami \\
\hline Instruments & \multicolumn{4}{|l|}{ siyanse } \\
\hline
\end{tabular}

Meat is a superordinate level that contains the loanwords on uncooked meat cuts coming from four categories: Pork cuts (eg. tito "pig's trip"), Beef cuts (eg. goto "ox trip"), Fowls (eg. ulikba "white-feathered or light-skinned fowls with dark meat"), and Fish and sea food (eg. tuwabak "big-eyed herring").

Vegetable covers all loanwords on uncooked vegetables. There is no further distinction made within this category, for example, petsay "Chinese cabbage" and kintsay "celery".

Soybean product is also a category by itself. It covers all loanwords on uncooked bean products. For example, tokuwa "soybean curd", tahuri "fermented salted soybean curd".

Rice constitutes a category by itself. It covers all loanwords on uncooked rice products, such as bihon "rice noodles".

Flour product also constitutes a category itself. It covers all loanwords on uncooked flour products. Examples are miki "thick flour noodles" and misuwa "thin flour noodles".

The above mentioned eight categories all fall under the level of Raw. There are three categories under the level of Cooked: Food preparation, Type of food, and Manner of cooking.

Food preparation is a whole category by itself. It contains all the loanwords which are used in the preparation of food, such as spices, seasoning and other food preservatives. For example, angkak "red-colored grains of rice used as coloring for food" and kelwa "powdered mustard".

Type of food, like the categories under Raw, includes five categories: Meat, Vegetables, Soybean products, Fish and sea food, Rice products and Flour products. The five categories which are directly superordinated by the level Raw, are under the level Type of food, which is the category directly superordinated by the level of Cooked. The categories that are included in Type of food can be further distinguished by the presence of certain modifiers such as toge guisado or kintsay guisado. The same thing will not happen in the categories under the level of Raw.

Manner of cooking is a superordinate level that includes four categories: Fried (eg. ukoy "fried flour cake consisting of grated squash, carrots or toge with shrimps"), Boiled and steamed (eg. siyopaw "steamed rice cake with meat and condiments inside"), Stewed (eg. humba "highly spiced dish of pork or chicken"), and Soupy (eg. mami "dish or noodles cooked in soup style").

Instruments constitutes only category by itself. It includes all the loanwords that refer to cooking utensils and other devices. There are only five loanwords belong to this category: siyanes "frying spoon", lansong "cooking apparatus make of bamboo split fixed in a tin ring used for steaming", bithay "rice sifter", pohiya "ladle made of gourd or wood", and bilao "device for winnowing rice".

\section{B. Lexical Content of Hokkien Loanwords on Cookery}

As previously mentioned, Thorp (1972) made the lexical content of the lexical entries in Panganiban (1966). The finding shows the percentage of foreign origin and that of Tagalog in origin: $58 \%$ Tagalog origin; 33\% Spanish origin; 4\% Malay origin; 3\% Chinese origin; and the rest origin of English, Sanskrit and Arabic.

Yap (1974) used the technique to determine the lexical content of the Hokkien loanwords on cookery. The above mentioned taxonomic analysis of the Hokkien loanwords on cookery was made with the view of setting up the categories necessary for an in-depth analysis of loanwords in this domain resulting in a total of nineteen categories. Then, the Hokkien loanwords were classified properly.

In this section, the percentage of the total number of loanwords in each taxonomic category is determined. One thing that needs to be mentioned is that the five categories appearing under the higher categories of both Raw and Cooked only once, which meant cutting the total number down to fourteen. Table 3 shows the total percentage of loanwords within each culinary category. 
TABLE 3:

PERCENTAGE OF THE TOTAL NUMBER OF HOKKIEN LOANWORDS IN EACH CULINARY CATEGORY (YAP, 1974, P. 148)

\begin{tabular}{|c|c|c|c|}
\hline Culinary Category & Total No. & No. of loanwords & Percentage \\
\hline 1. Pork cuts & 63 & 4 & $6.3 \%$ \\
\hline 2. Beef cuts & 63 & 4 & $6.3 \%$ \\
\hline 3. Fowls & 63 & 1 & $1.6 \%$ \\
\hline 4. Fish and sea food & 63 & 4 & $6.3 \%$ \\
\hline 5. Vegetables & 63 & 8 & $12.7 \%$ \\
\hline 6. Flour products & 63 & 2 & $3.2 \%$ \\
\hline 7. Soy bean products & 63 & 6 & $9.5 \%$ \\
\hline 8. Rice products & 63 & 2 & $3.2 \%$ \\
\hline 9. Fried & 63 & 3 & $4.8 \%$ \\
\hline 10. Boiled and steamed & 63 & 8 & $12.7 \%$ \\
\hline 11. Stewed & 63 & 6 & $9.5 \%$ \\
\hline 12. Soupy & 63 & 3 & $4.8 \%$ \\
\hline 13. Food preparation & 63 & 7 & $11.1 \%$ \\
\hline 14. Instrument & 63 & 5 & $8 \%$ \\
\hline Total & & 63 & $100 \%$ \\
\hline
\end{tabular}

The categories given below are in the order of their rank of percentage:

1. Vegetables $(12,7 \%)$; Boiled and steamed $(12.7 \%)$

2. Food preparation $(11.1 \%)$

3. Soy bean products $(9.5 \%)$; Stewed $(9.5 \%)$

4. Instruments $(8 \%)$

5. Pork cuts $(6.3 \%)$; Beef cuts $(6.3 \%)$; Fish and other sea food $(6.3 \%)$

6. Fried (4.8\%); Soupy (4.8\%)

7. Flour products $(3.2 \%)$; Rice products $(3.2 \%)$

8. Fowls $(1.6 \%)$

On the basis of the analysis some conclusions can be suggested.

First, among the raw materials, the category of Vegetables was introduced at the highest percentage to Tagalog speakers. It suggests that these vegetables were either brought into the country by the Hokkiens or were found locally but the culinary potentialities were unknown to the Tagalog Speakers. Boiled and steamed method of cooking is common among Hokkien speakers, but previously uncommon among Tagalogs. Therefore, it is not surprising that Tagalog had borrowed heavily in this category.

Second, various ways of food preparation were introduced by the Hokkien people because the way of food preparation of the Tagalog speakers were probably less varied. Thorp (1972) also noted that "it is more likely for a group to accept new ways of preparing raw materials, rather than accept new raw materials or new names for things that have already been identified" (as cited in Yap, 1974, p. 149).

Third, next to boiled and steamed, as a manner of cooking, the use of soy bean for food production or stewed is very common to the Hokkien people. The loanwords under the categories of Rice products and Fowls are shown the lowest percentage. It conforms to the cultural facts that rice is the staple crop of the Tagalogs and that fowls had been a source of food among the Tagalogs for long time. Tagalog speakers might have already possessed the words appropriate for the referents under the categories. Table 4 shows the distribution of percentages on a higher level of categorization.

TABLE 4:

PERCENTAGE OF THE TOTAL Number OF HOKKIEN LOANWORDS DistRIBUTED AMONG THE MAJOR CATEGORIES OF RAW, COOKED AND INSTRUMENTS

\begin{tabular}{|l|l|l|l|}
\hline \multicolumn{5}{|l|}{ (YAP, 1974, P. 152) } \\
\hline Major Categories & Total No. & No. of loanwords & Percentage \\
2. Raw $\quad$ Cooked & 63 & 31 & $49.2 \%$ \\
3. Instruments & 63 & 27 & $42.8 \%$ \\
\hline Total & 63 & 5 & $8 \%$ \\
\hline
\end{tabular}

The analysis shows that the great number of Hokkien contribution to the domain of Tagalog cookery is in terms of the category Raw whose percentage is greater than the percentages of the rest of the categories. The finding suggests that the Tagalogs had a lot of untapped raw materials, on the other hand, the eating habit and food preparation of Hokkien speakers were more developed. The percentage of category Cooked is not much lower than the category Raw. The high percentage of loanword in the category Cooked implies the simple way of cooking and food preparation of Tagalog speakers, which may have made them easily accept new terms and modes of cooking and food preparation. Yap (1974, p. 153) conjectured the low percentage of loanwords under the category of Instruments: the Tagalog speakers' interest lay in newer ways of preparation, or they must have had utensils adequate for the preparation of the new kinds of cookery.

\section{Semantic Shift of Hokkien Loanwords on Cookery}

According to Bloomfield (1933, p. 425), semantic shift or semantic change refers to the process by which the meaning of a loanword is shifted from its original meaning to something that is similar or closely related to the original. 
He attempted to make the classification of semantic shifts based on the "logical relations of successive meanings, such as narrowing, widening, metaphor, metonymy, synechdoche, hyperbole, degeneration, elevation.

Not many Hokkien loanwords on cookery have undergone semantic shift. Those that have undergone the shift can all be classified under widening, as shown in Table 5.

TABLE 5:

HOKKIEN LOANWORDS UNDERGONE SEMANTIC SHIFT (YAP, 1974, P159-161)

\begin{tabular}{|c|c|c|c|}
\hline Present Tagalog words & Present meaning & Hokkien original words & Original meaning \\
\hline $\begin{array}{l}\text { pancit } \\
\text { pancit mami }\end{array}$ & $\begin{array}{l}\text { a frying noodle dish; } \\
\text { a soupy noodle dish }\end{array}$ & pianesit & $\begin{array}{l}\text { something that is conveniently } \\
\text { cooked }\end{array}$ \\
\hline huma & pork dish; chicken dish & humba & pork dish \\
\hline $\begin{array}{l}\text { pesa } \\
\text { pesang manok }\end{array}$ & $\begin{array}{l}\text { plain boiled (cooking of fish); } \\
\text { chicken boiled in water }\end{array}$ & $\begin{array}{l}\text { peqsaqhi } \\
\text { (-hi means “fish") }\end{array}$ & plain boiled (cooking of fish) \\
\hline lumpiya & $\begin{array}{l}\text { Not only the original } \\
\text { ingredient, but other kinds of } \\
\text { ingredients like ubod "pith of } \\
\text { coconut trunk" and labong } \\
\text { "bamboo shoots" }\end{array}$ & lumpiya & $\begin{array}{l}\text { a dish in which vegetables like } \\
\text { carrots, cabbage, string beans, and } \\
\text { tokuwa are sliced into thin pieces, } \\
\text { mixed and stewed until cooked }\end{array}$ \\
\hline ukoy & $\begin{array}{l}\text { flour is used as a substitute for } \\
\text { gabi, with the main ingredient } \\
\text { being a species of small } \\
\text { shrimps, and made by } \\
\text { deep-frying the mixture of } \\
\text { flour and shrimps }\end{array}$ & okue & $\begin{array}{l}\text { Cake made from gabi; made by } \\
\text { steaming the mixted ingredients, } \\
\text { ehich can be eaten as is or after it } \\
\text { has been deep-fried. }\end{array}$ \\
\hline batsoy & $\begin{array}{l}\text { The ingredients range from } \\
\text { kidney, pancreas, liver and to } \\
\text { loin of pork. }\end{array}$ & batsoy & $\begin{array}{l}\text { A dish with loin of pork as its main } \\
\text { ingredient }\end{array}$ \\
\hline suam & $\begin{array}{l}\text { A dish of either sugpo } \\
\text { "prawns" as in sugpo sinuam, } \\
\text { or hipon "shrimps" as in hipon } \\
\text { sinuam cooked in a soupy } \\
\text { style with rice added. }\end{array}$ & $\begin{array}{l}\text { suam (-am means "the broth } \\
\text { from rice porridge") }\end{array}$ & cook the broth from rice porridge \\
\hline taho & $\begin{array}{l}\text { soy bean curd that is cooked } \\
\text { and is eaten with brown syrup }\end{array}$ & tauhu & Soy bean curd that is uncooked \\
\hline
\end{tabular}

\section{CONCLUSION}

This paper has attempted to examine the Tagalog loanwords of Hokkien origin in the domain of cookery through the semantic analyses. Taxonomic analysis to the Hokkien loanwords on cookery provided superordinate and subordinate levels which showed the hierarchical relationships of the lowest-level categories to the highest-level ones. Percentages of loanwords under each category on three different levels were taken into consideration. Based on the analysis, generalization on the nature of loanwords in the domains was made.

The study showed that on the highest superordinate level, the greatest number of Hokkien loanwords came from the category of Raw, followed by that of Cooked. The category of instruments had the lowest percentage. Under the level of Raw, the category meat had the highest percentage, followed closely by that of vegetables, and next, by that of Soy bean products. The percentage of Flour and rice products is significantly lower than those of the former three categories. Under the level of manner of cooking, the category Boiled and steamed had the highest percentage. All these findings revealed the fact that these terms of food and ways of cooking which were commonly identified with the Hokkien people were readily accepted by the Tagalog speakers.

\section{REFERENCES}

[1] An Introduction to Taiwanese Vocabulary. LearnTaiwanese.org. http://learntaiwanese.taioaan.org/ vocab_taigie. html (accessed 2/7/2011).

[2] Beyer, H. Otley. (1948). Early history of Philippine relations with foreign countries, especially China. In Arsenio Manuel's Chinese elements in the Tagalog language. Manila: Filipiniana Publications.

[3] Bazell, C.E. (1953). Linguistic form. Istanbul: Istanbul Press.

[4] Bloomfield, Leonard. (1933). Language. New York: Holt, Rinehart \& Winston.

[5] Branner, David Prager (2000). Problems in Comparative Chinese Dialectology - the Classification of Miin and Hakka. Trends in Linguistics series, no. 123. Berlin: Mouton de Gruyter.

[6] Crowley, T. (1997). An introduction to historical linguistics ( $3^{\text {rd }}$ edition). Auckland, Oxford, and New York: Oxford University Press.

[7] Crystal, David. (1997). The Cambridge Encyclopedia of Language. UK: Cambridge University Press.

[8] Frake, Charles. (1964). The diagnosis of disease among the Subanons of Mindanao. In Dell Hymes' Language in culture and society. New York: Harper\& Row Publishers.

[9] French, Koleen Matsuda. (1988). Insights into tagalong Reduplication, infixation, and stress from nonlinear phonology. A publication of Summer Institute of Linguistics and the University of Texas are Arlington. 
[10] Kane, Daniel (2006). The Chinese language: its history and current usage. North Clarendon, VT: Tuttle Publishing. pp.100-102

[11] Panganiban, Jose Villa. (1966). Talahuluganang Philipino-Ingles. Maynila: kagawaran ng Palimbagan.

[12] Philippine Census, (2000). Table 11. Household Population by Ethnicity, Sex and Region: 2000.

[13] Ramos, Teresita V. (1971). Tagalong structure. Honolulu: University of Hawai'i Press.

[14] Ramos, Teresita V. and Resty M Ceña,. (1990). Modern Tagalog. Honolulu: University of Hawai‘i Press.

[15] Schachter, Paul, and Fe T. Otanes. (1972). Tagalog reference grammar. Berkeley, Los Angeles, London: University of California Press.

[16] Throp, John. (1972). The lexical content of Tagalog and the culture of the Philippines. Unpublished paper. Manila: Ateneo de manila University.

[17] Wales. Jimmy. (2001). Tagalog language. http://en.wikipedia.org/wiki/Tagalog_grammar (accessed 3/4/2005).

[18] Yap, Gloria Chan. (1974). Hokkien Chinese borrowings in tagalong. Unpublished Ph.D dissertation. Manila: Ateneo de Manila University.

[19] Yap, G.loria Chan. (1976). The semantics of Tagalog kinship terms of Hokkien Chinese origin, Philippine Journal of Linguistics vol. 7, 1-2

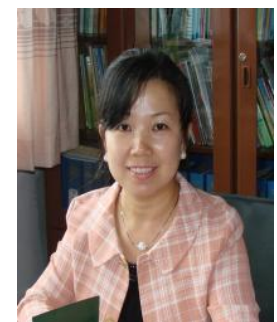

Xuebo Cui was born in Yanji, China in 1974. She received her PH.D degree in Applied Linguistics from De La Salle University, the Philippines in 2007. Dr. Cui currently heads the Department of English at Yanbian University, Yanji, China. Her research interests include contrastive linguistics, professional development for teachers of English, and bilingual education. Dr. Cui is a member of TESOL. 